\title{
Service Role and Outcome as Moderators in Intercultural Service Encounters
}

Purpose - We introduce a comprehensive framework incorporating service roles (customer vs. employee) and outcomes (failure vs. success) as moderators in the process by which perceived cultural distance affects customers and employees in intercultural service encounters.

Design/methodology/approach - 2 X 2 X 3 between-subjects experimental design with Chinese undergraduate students, manipulating service role (customer and employee), outcome (failure and success) and perceived cultural distance (low, medium and high).

Findings - Compared to service employees, customers perceive higher cultural distance and lower interaction comfort, service quality and satisfaction, and stronger negative moderating effect of perceived cultural distance in intercultural service encounters. Compared to service success, failure results in lower interaction comfort, perceived service quality and satisfaction, and these effects are stronger for customers (vs. employees).

Research limitations/implications - We used shorter versions of all the scales to minimize participant fatigue and to increase their involvement along with an experimental design with imaginary service scenario, both of which may restrict the generalizability of our findings. Practical implications - Service managers should focus on customer education and employee training to reduce the negative impact of perceived cultural distance and prevent service failure rather than try to improve service quality and satisfaction beyond customers' expectations.

Originality/value - We extend prior research by exploring the moderating effects of service role (customer vs. employee) and outcome (success vs. failure) on the direct and indirect effects of perceived cultural distance on interaction comfort, service quality and satisfaction.

Keywords - Intercultural, perceived cultural distance, satisfaction, service encounter, service outcome, service quality, service role

Paper type - Research paper 


\section{Service Role and Outcome as Moderators in Intercultural Service Encounters}

\section{INTRODUCTION}

With rapid increase in international travel and migration in recent years, there is a rise in the number and importance of intercultural service encounters, which involve interactions between customers and employees from different cultures (Teng, 2011, Etgar and Fuchs, 2011, Wang and Mattila, 2010). In fact, in 2010 alone, about 980 million tourists traveled outside their home country, spending about US\$ 919 billion (UNWTO, 2012) and about 214 million migrants lived outside their countries of birth (UNDESA, 2011). These two groups account for about 1.2 billion people (17.5\% of world population) and billions of intercultural service encounters.

Despite such increasing importance of intercultural service encounters, prior research mostly explores the influence of culture on customer perceptions and reactions (Liu et al., 2001, Zhang et al., 2008) but generally ignores the impact of cultural differences on the interaction between customers and employees from diverse cultural backgrounds. A few studies use the customers' perspective to explore the role of culture shock (Stauss and Mang, 1999), perceived discrimination (Barker and Härtel, 2004), and behavioral biases in the employees' responses (Martin and Adams, 1999, McCormick and Kinloch, 1986). More recent studies seek deeper insights, albeit mostly from the customers' perspective, by exploring the role of cross-cultural interaction comfort (Paswan and Ganesh, 2005), ethnocentrism (Ueltschy et al., 2007, Javalgi and Martin, 2007, Sharma, 2005), ethnic/cultural dissimilarity (Etgar and Fuchs, 2011), and reactions to service failure and recovery (de Matos et al., 2011, Wang and Mattila, 2011).

A few studies have investigated intercultural service encounters from the employees' perspective; for example, the role of intercultural sensitivity of service employees (Sizoo, 2006, Sizoo et al., 2005) and emotional stress and coping strategies used by them in intercultural 
service encounters (Wang and Mattila, 2010). However, generally they do not incorporate the employees' perspective (Mattila, 1999b, Mattila, 1999a) and thus provide only a limited view of the complex socio-psychological process underlying intercultural service encounters.

Sharma, Tam, and Kim (2009) address this gap with their intercultural service encounters (ICSE) framework, to explore the direct and indirect influence of perceived cultural distance and intercultural competence on inter-role congruence, interaction comfort, adequate and perceived service levels, and satisfaction, from the perspective of both customers and employees. Wang and Mattila (2010) extend this work by exploring the stress and negative emotions experienced by the service employees in intercultural service encounters and the different coping strategies used by them to deal with these negative outcomes. However, both these papers are conceptual in nature and only use some qualitative data to support their respective conceptual frameworks.

Sharma, Tam, and Kim (2012) extend this line of research using role theory (Solomon et al., 1985) to develop a modified ICSE framework incorporating differences between customers and employees and tested it with an empirical study. However, they left a few unanswered questions and research gaps. For example, they found a positive effect of perceived cultural distance on interaction comfort instead of the hypothesized negative effect (Gap 1). They also did not explore the direct effect of perceived cultural distance on service quality and customer satisfaction (Gap 2). Moreover, they did not operationalize service quality as a distinct construct and used perceived service level as its proxy (Gap 3). Finally, they tested their modified framework only for service failure and did not study successful service encounters; hence it is not clear if their framework and findings may apply to both service failure and success (Gap 4).

We address all the above gaps in this paper with a more comprehensive framework that incorporates both service role (customer vs. employee) and outcome (failure vs. success) as 
moderators in the intercultural service encounters and includes perceived service quality as a distinct construct. We also hypothesize differences in the impact of perceived cultural distance on interaction comfort, perceived service quality and satisfaction, based on service role, service outcome and their interaction with each other. We describe our results from an experimental study that supports all our hypotheses and discuss the conceptual contribution and managerial implications of this research, along with some limitations and directions for future research.

\section{THEORETICAL BACKGROUND}

\section{Service Role (Customers vs. Employees)}

According to role theory, interpersonal service encounters are social interactions with clearly defined roles and scripts (Solomon et al., 1985) and deviations from these scripts can create dissatisfaction for both customers and employees (Bitner et al., 1997). In other words, the outcome of a service encounter depends on the attitudes and behaviors of both customers and employees (Solomon et al., 1985). Using this perspective, Sharma et al. (2009) argue that due to a lack of understanding of and agreement with each other's roles, both customers and employees may experience greater confusion, misunderstandings and dissatisfactory service experience.

Service customers and employees both play an important role in service encounters involving human interaction, as they work together to co-create the service (Gremler and Gwinner, 2000). Moreover, customers and employees are both human beings and hence they are likely to be affected by their feelings and thoughts during the service encounters. However, customers and employees also show differences in attitudes, behaviors, expectations, perceptions and evaluations of their service experiences (Bitner et al., 1994, Bitner et al., 1997). 
In most situations, customers have more choice than employees, in terms of who they wish to interact with during a service encounter (Nagel and Cilliers, 1990). Second, service employees may have more knowledge about the service delivery process and its constraints, which can make their expectations more realistic than those of customers (Mudie, 2003). Third, compared to customers, service employees are expected to be more objective and professional in a service encounter (Gremler et al., 1994). Finally, unlike customers, service employees are bound by the employment conditions of their employers, which can directly affect the efficiency, quality, and punctuality of their performance (Mudie, 2003).

Prior research shows that just like customers, service employees may also prefer interacting (e.g., smile, thank, establish eye contact) with customers from similar ethnic and demographic profiles (Martin and Adams, 1999, McCormick and Kinloch, 1986). However, many studies also show significant differences between the perceptions and judgments of customers and employees due to differences in their attitudes, knowledge and experience (e.g., Bitner et al., 1994, Chi and Gursoy, 2009, Chung-Herrera et al., 2004).

\section{Perceived Cultural Distance (PCD)}

Cultural distance is the extent to which two cultures are different from each other in terms of various cultural elements, such as ethnicity, language, social structure, religion and values (Triandis, 1994). Based on this, Sharma et al. (2009) define perceived cultural distance as the extent to which people from one culture find those from other cultures different from them in terms of ethnicity, nationality, language, values and customs. According to Sharma et al. (2009), a lower perceived cultural distance between customers and employees may facilitate their communication with each other and improve the quality of their interaction and its outcomes. 
Prior research shows mixed findings about the influence of perceived cultural distance in intercultural service encounters (e.g., Sharma et al., 2012). For example, PCD has a positive influence on the satisfaction of Japanese, American and German passengers of a German airline in intercultural service encounters (Stauss and Mang, 1999). Stauss and Mang (1999) explained this on the basis of downward adjustments in customers' expectations as they may attribute the service failure to the cultural differences. Weiermair (2000) reports similar findings from several studies with his colleagues in Austria, which show that customers are less demanding and more tolerant when dealing with culturally distant service providers, although this effect may vary across different service quality dimensions. Warden, Liu and Huang (2003) found similar results with consumers in Taiwan and show that the relatively higher satisfaction in intercultural service encounters could be due to a greater customer acceptance of recovery strategies.

In contrast, others show that customers may prefer being served by employees with the same nationality (Harrison-Walker, 1995, Ali-Sulaiti and Baker, 1998) or the same race as them (Kulik and Holbrook, 2000), possibly due to smaller perceived cultural distance, greater trust and familiarity. In fact, customers also use salient cultural identity cues to self-select service providers with similar cultural characteristics (Hopkins et al., 2005). Notwithstanding this mixed evidence about the influence of perceived cultural distance, most prior studies focus on the perceptions and judgments of 'service customers', with hardly any efforts to explore the effect of perceived cultural distance on the perceptions and judgments of 'service employees' (Sharma et al., 2012). Moreover, most existing studies focus on the cases of service failure and ignore successful service encounters; hence it is not clear whether perceived cultural distance has a similar impact on the perceptions of customers and employees and whether the outcome of the service encounters is a failure or a success. We focus on these gaps in this paper. 


\section{CONCEPTUAL FRAMEWORK AND HYPOTHESES}

\section{Interaction Comfort (IC)}

Interaction comfort (also known as consumer comfort) is defined as a psychological state in which customers feel calm and peaceful, and not anxious, worried, or insecure in a service encounter (Spake et al., 2003). Interaction (or consumer) comfort has a positive influence on the consumer trust, commitment, perceived service quality, and satisfaction with the service provider (Dabholkar et al., 2000). Sharma et al. (2009) use the similarity-attraction paradigm (Byrne, 1997) to propose that the cultural similarity in terms of language, values, and norms between customers and employees may facilitate their communication with each other and improve the quality of their interaction and their satisfaction with the outcome.

Prior research shows mixed results for the influence of perceived cultural distance on interaction comfort. For example, some show a negative influence of perceived cultural distance (Paswan and Ganesh, 2005) and a positive influence of cultural similarity (Hopkins et al., 2005). In contrast, Sharma et al. (2012) found a positive effect of perceived cultural distance on interaction comfort for customers and no significant effect for employees, which they explain as based on a possible confound in their study design. Prior research also ignores the differences between service failure and success (Sharma et al., 2012). We hypothesize a main effect of PCD on interaction comfort based on the similarity-attraction paradigm used by Sharma et al. (2009):

H1a: Perceived cultural distance has a negative effect on interaction comfort.

\section{Perceived Service Quality (PSQ)}

Perceived service quality is a global judgment or attitude based on customers' beliefs about the service (Parasuraman et al., 1988). For the intercultural service encounters, Sharma et 
al. (2009) use social identity theory (Tajfel et al., 1971) to argue that lower perceived cultural distance may help both customers and employees to identify each other as members of the same in-group, feel more comfortable in dealing with each other and display more tolerance toward each other. In contrast, greater perceived cultural distance generally leads to lower interaction comfort and perceived service quality (Paswan and Ganesh, 2005, Hopkins et al., 2005). Hence, we hypothesize a main effect of interaction comfort on perceived service quality, as follows:

H1b: Interaction comfort has a positive effect on perceived service quality.

\section{Satisfaction (SAT)}

Customer satisfaction with a service encounter is an emotional state experienced in response to an evaluation of their service experience (Oliver, 1997). Perceived employee effort (Mohr and Bitner, 1995) and performance (Dolen et al., 2004, Schneider and Bowen, 1985) have a positive effect on customer satisfaction. However, there is hardly any research on employee satisfaction with a service encounter and most studies explore employee satisfaction with their job showing that the employees generally feel higher overall satisfaction with their own performance if appreciated by customers and supervisors (Brown and Lam, 2008). Prior research on intercultural service encounters shows a positive effect of perceived service on satisfaction for both customers and employees (e.g., Sharma et al., 2012). However, most of these studies focus on service failures and ignore their role in successful service encounters. Moreover, they ignore the direct effects of perceived cultural distance on satisfaction, thus not providing a complete picture. Therefore, we hypothesize the following main effects:

H1c: Perceived service quality has a positive effect on satisfaction.

H1d: Perceived cultural distance has a negative effect on satisfaction. 


\section{Service Role (Customers vs. Employees)}

Compared to customers, service employees generally have a greater chance to interact more frequently with people from diverse cultures. Moreover, the training provided by the employers to the service employees may also make them more familiar with the differences and similarities with people from other cultures (Mudie, 2003), possibly making them more objective by reducing their perceived cultural distance and increasing their interaction comfort, perceived service quality and satisfaction in intercultural service encounters (Gremler et al., 1994).

In contrast, most customers do not have the training or the motivation to adjust their expectations in intercultural service encounters, which may result in significant differences in their expectations and perceptions of the same service encounter compared to the employees (Bitner et al., 1994). Customers are also more likely to react and respond to the behavior of employees rather than the other way around (Bitner, 1990). Based on the above, we hypothesize that customers may perceive greater cultural distance and lower interaction comfort, service quality and satisfaction, compared to the employees. Hence, we hypothesize as follows:

H2: $\quad$ Compared to service employees, customers perceive significantly a) higher cultural distance, $\boldsymbol{b})$ lower interaction comfort, $\boldsymbol{c}$ ) lower service quality, and d) lower satisfaction, in intercultural service encounters.

Sharma et al. (2009) proposed that perceived cultural distance may have a negative effect on interaction comfort for both customers and employees. However, their subsequent empirical results showed a significant positive effect and that too only for customers (Sharma et al., 2012), a finding quite similar to Stauss and Mang (1999) who found a positive influence of perceived cultural distance on customer satisfaction. Both these researchers explain their findings by suggesting that customers may adjust their expectations based on the perceived cultural distance 
with the service providers. However, they do not explain why the employees may not also adjust their expectations in such situations and whether similar results can be seen in successful service encounters for both service customers and employees.

As argued by Sharma et al. (2012), frontline service employees are trained and required to be less emotional and more tolerant with culturally distant customers, whereas customers do not have any such constraints. Therefore, the influence of perceived cultural distance on interaction comfort may be stronger for customers compared to service employees. Moreover, unlike customers, employees have access to more inside information about the actual reasons for service failure or success; hence, they may focus on other factors besides their own comfort level in evaluating a service encounter. In contrast, customers may be more emotionally involved in a service encounter and may not have access to inside information; hence they may rely to a greater extent on their own interaction comfort to evaluate the perceived service quality and satisfaction in an intercultural service encounter. Hence, we hypothesize as follows:

H3: Compared to service employees, customers experience a significantly stronger a) negative effect of perceived cultural distance on interaction comfort, b) positive effect of interaction comfort on perceived service quality, c) positive effect of perceived service quality on satisfaction, and d) negative effect of perceived cultural distance on satisfaction, in intercultural service encounters.

\section{Service Outcome (Failure vs. Success)}

Prior research on 'self-serving attributional bias' shows that people generally exhibit a self-enhancing bias for their success (i.e., give internal attributions or take credit for success) and a self-protecting bias for their failures (i.e., give external attribution or blame others for failure) (Bradley, 1978). Using this concept in the services context, one would expect service employees 
to blame the customers or other external factors for service failures, and customers to blame the service employees or other factors beyond their control, resulting in significantly different views of the same service encounter (Bitner et al., 1994). In fact, many studies show significant differences between the perceptions and evaluations of customers and employees of their experience in a service encounter, although these differences are generally more salient in the case of service failure compared to success (Bitner et al., 1994).

For example, Chung-Herrera et al. (2004) show that customers and employees may have similar perceptions of service failures with good recovery efforts but very different perceptions of service failures with poor recovery effort. However, prior research on intercultural service encounters focuses on service failures and recovery strategies (e.g., Stauss and Mang, 1999, Wang and Mattila, 2011, Warden et al., 2003, Weiermair, 2000, Sharma et al., 2012), hence it is not clear how the differences in the customer and employee perceptions may influence their service experience in successful intercultural service encounters.

Specifically, the desire for self-enhancement may lead both customers and employees to give themselves credit for any success; however, unlike the employees who get paid to provide the service, the customers actually pay for the service, hence they are possibly more likely to experience such a bias (Bitner et al., 1994). As a result, the difference between the perceptions of customers and employees due to the self-serving attributional bias may be greater in service failure than in service success situations. In other words, customers may experience significantly lower interaction comfort, service quality and satisfaction in a service failure compared to service employees and vice versa in service success. Therefore, we hypothesize as follows: 
H4: $\quad$ Compared to service success, service failure results in a significantly lower a) interaction comfort, b) perceived service quality, and c) satisfaction, in intercultural service encounters.

H5: $\quad$ Compared to service employees, customers perceive significantly greater differences in a) interaction comfort, b) service quality, and c) satisfaction, between service failure and success, in intercultural service encounters.

'Correspondence bias' is a fundamental phenomenon in social psychology and it is defined as the tendency to draw conclusions about other people's individual characteristics from their behaviors instead of the situational context in which they occur (Gilbert and Malone, 1995). Prior research describes four mechanisms underlying this bias, namely lack of awareness, unrealistic expectations, inflated categorizations, and incomplete corrections. In the context of intercultural service encounters, it is quite likely to see the first two mechanisms at work. Specifically, customers and employees from diverse cultural backgrounds may lack awareness of each other's service roles, which may result in unrealistic expectations.

We argue that the 'self-serving attributional bias' described above may in fact interact with the 'correspondence bias', wherein customers and employees may not only blame each other for failure and take credit for success, they may also draw conclusions about each other due to a lack of awareness of each other's service roles and the resulting unrealistic expectations of the intercultural service encounter. As a result, we expect the influence of perceived cultural distance, interaction comfort and perceived service quality to be stronger in a service failure compared to success for both service customers and employees. Hence, we hypothesize:

H6: $\quad$ Compared to service success, service failure results in a significantly stronger a) negative effect of perceived cultural distance on interaction comfort, b) positive 
effect of interaction comfort on perceived service quality, c) positive effect of perceived service quality on satisfaction, and d) negative effect of perceived cultural distance on satisfaction, in intercultural service encounters.

Figure 1 (H1-H3) and Figure 2 (H4-H6) summarize all the hypotheses.

$<$ Insert Figures $1 \& 2$ about here $>$

\section{METHODOLOGY}

\section{Sample and Procedure}

We used a 2 X 2 X 3 between-subjects experimental design by manipulating service role (customer vs. employee), service outcome (success vs. failure) and perceived cultural distance (low, medium and high) using twelve versions of an intercultural service encounter scenario in a restaurant setting with 300 undergraduate business students at a large university. In order to disguise the real purpose of the study from the participants, to prevent hypotheses guessing and to make them participate seriously, we told them that it was a study of consumer behavior and that the data collected would be used in one of their tutorials.

We developed several versions of service failures and successes in diverse service categories and tested them with samples drawn from the same undergraduate population as used in the main study, to ensure that they could imagine themselves being in such situations in real life, either as a customer or an employee. Based on our findings, we chose a restaurant setting with two scenarios (success vs. failure) shown in Exhibit A and B as these got the highest scores (using seven-point Likert-type scales) for the extent to which they represented service failure (M $=5.68, \mathrm{SD}=.87)$ or success $(\mathrm{M}=5.34, \mathrm{SD}=1.11)$ as well as realism $(\mathrm{M}=4.87, \mathrm{SD}=1.44)$, relevance $(\mathrm{M}=4.93, \mathrm{SD}=1.56)$ and credibility $(\mathrm{M}=5.12, \mathrm{SD}=1.38)$.

$<$ Insert Exhibits A \& B about here > 
We randomly assigned 25 participants to each of the twelve conditions and asked them to complete a structured questionnaire, which described an intercultural service encounter (success or failure) and asked the participants to assume a service role (customer or employee) while imagining themselves to be in that situation before answering a few questions. We used three photos of males (Chinese, South-Asian and Caucasian) to manipulate the ethnicity of the target person in order to prime different levels of perceived cultural distance for the participants in this study, all of whom shared the same ethnicity and nationality (Chinese).

We used another set of pretests to choose photos that allowed us to manipulate perceived cultural distance while controlling for other possible confounding factors. Based on our findings, we chose three photos that showed a significant difference $(F(2,57)=15.63, p<.001)$ in the average scores for PCD (M = 3.48 (Chinese), 4.35 (South-Asian), 5.33 (Caucasian)) but no significant differences in the scores for attractiveness $(\mathrm{M}=3.63,3.47,3.58 ; \mathrm{F}(2,57)=.81, \mathrm{p}>$ $.45)$, likeability $(\mathrm{M}=3.51,3.43,3.62 ; \mathrm{F}(2,57)=1.21, \mathrm{p}>.35)$ and believability $(\mathrm{M}=4.38,4.24$, $4.43 ; \mathrm{F}(2,57)=1.08, \mathrm{p}>.40)$. We used these three photos in a randomized manner in order to avoid any systematic bias in the allocation of participants to any experimental condition.

\section{Measures}

We adapted the following well-established scales to measure all the constructs:

- Perceived cultural distance: Five items from 'psychic distance' scale (Sousa and Bradley, 2006) used in other intercultural studies (e.g., Ng et al., 2007, Sharma et al., 2012), with a seven-point Likert response format.

- Interaction comfort: Three items from 'consumer comfort' scale (Spake et al., 2003), with a seven-point Semantic Differential response format. 
- Perceived service quality: Three items from 'overall service quality' scales (e.g., Zeithaml et al., 1996), with a seven-point Semantic Differential response format.

- Satisfaction: Three items from 'customer satisfaction' scales (e.g., Seiders et al., 2005, Brady et al., 2005), with a seven-point Semantic Differential response format.

All the participants were reminded to respond to the above scales from their perspective as a customer or employee based on the condition assigned to them. Specifically, a participant assigned to the role of customer responded to the perceived cultural distance, interaction comfort, service quality and satisfaction experienced by them as a customer; whereas a participant assigned to the role of employee responded to the perceived cultural distance, interaction comfort, service quality and satisfaction experienced by them as an employee.

\section{DATA ANALYSIS AND FINDINGS}

We began with an assessment of the psychometric properties of all the scales, using confirmatory factor analysis with AMOS 22.0. The measurement model shows an excellent fit $\left(\chi^{2}=110.58, d f=71, \chi^{2} / d f=1.56, \mathrm{CFI}=.97, \mathrm{NFI}=.95, \mathrm{RMSEA}=.043\right)$ with all the fit indices better than their cut-off values $\left(\mathrm{CFI}>.95, \mathrm{NFI}>.90, \mathrm{RMSEA}<.06,1 \leq \chi^{2} / d f \leq 3\right)$. All the factor loadings are higher than .60 with large and significant $(p<.001)$ t-values and no major crossfactor loadings (all less than .40). Table 1 shows the psychometric properties of all the scales.

$<$ Insert Table 1 about here $>$

All the parameter estimates $(\lambda)$ are significantly different from zero at the $5 \%$ level, showing a high degree of convergent validity, and none of the confidence intervals of the correlation coefficients for each pair of scales ( $\Phi$ estimates) includes 1.0, showing discriminant validity (Anderson and Gerbing, 1988). For another test of discriminant validity, we constrained the estimated correlation parameter between each pair of the four factors to 1.0 using six separate 
models and found the $\chi^{2}$ values for all these constrained models to be significantly higher than for the unconstrained model. Hence, none of the factors are perfectly correlated, which provides further support for their discriminant validity (Anderson and Gerbing, 1988).

All the scales are reliable with construct reliabilities ( 0.82 to 0.86$)$ higher than .60 (Bagozzi and $\mathrm{Yi}, 1988)$. Average variance extracted for each construct (.66 to .72) is greater than .50 and higher than the square of its correlation with the other constructs, providing further evidence of discriminant validity (Fornell and Larcker, 1981). Table 2 shows the correlations matrix with composite reliability, average variance extracted and descriptives for all the scales.

$<$ Insert Table 2 about here $>$

Next, we analyzed the direct and indirect effects of the three manipulated variables (PCD, Role and Outcome) on all the measured variables (IC, SQ and SAT) using multivariate analysis of variance (MANOVA). First, we checked the manipulation of PCD by comparing the average PCD scores across the three ethnicity conditions (Chinese, South Asian and Caucasian) using one-way analysis of variance (ANOVA) and found a significant difference $(F(2,288)=54.37, p$ $<.001)$, with the lowest score for the Chinese target person $(\mathrm{M}=3.57, \mathrm{SD}=1.17)$ followed by the South-Asian $(M=4.46, \mathrm{SD}=1.18)$ and the Caucasian $(\mathrm{M}=5.24, \mathrm{SD}=1.32)$, as shown in Table 3. Hence, our manipulation of target person's ethnicity is successful in priming PCD for the participants in all the conditions, in the expected direction. Next, we found significantly higher scores of $\operatorname{IC}(F(2,288)=8.24, p<.001)$ and $\operatorname{SAT}(F(2,288)=9.07, p<.001)$ for Chinese target person followed by South-Asian and Caucasian respectively. Thus, PCD has a negative influence on both IC (H1a) and SAT (H1d), as hypothesized.

$<$ Insert Table 3 about here $>$ 
We also found a significant effect of service role on $\operatorname{PCD}(F(1,288)=7.86, p<.001)$, IC $(F(1,288)=10.24, p<.001), \operatorname{SQ}(F(1,288)=15.33, p<.001)$ and SAT $(F(1,288)=17.74, p<$ $.001)$, such that compared to employees, customers perceive greater PCD (H2a), lower IC (H2b), lower SQ (H2c) and lower SAT (H2d). Similarly, service outcome has a strong impact on IC $(F(1,288)=71.56, p<.001), \operatorname{SQ}(F(1,288)=145.76, p<.001)$ and $\operatorname{SAT}(F(1,288)=134.49, p<$ $.001)$ as reflected by lower IC (H4a), SQ (H4b) and SAT (H4c) in service failure compared to success scenarios. We also found a significant interaction between service role and outcome for $\operatorname{IC}(F(1,288)=13.07, p<.001)$, SQ $(F(1,288)=40.96, p<.001)$ and $\operatorname{SAT}(F(1,288)=35.51, p<$ $.001)$ with greater differences in IC (H5a), SQ (H5b) and SAT (H5c) between service success and failure, for customers compared to the employees, hence H5a-H5c are also supported.

$<$ Insert Table 4 about here $>$

Next, we used structural equation modeling with AMOS 22.0 to find a positive influence of IC on SQ $(\beta=.32, p<.01)$ and SQ on SAT $(\beta=.36, \mathrm{p}<.01)$, as hypothesized in H1b and $\mathrm{H} 1 \mathrm{c}$ respectively. We then used multi-group comparison with structural equation modeling to compare the strength of the four hypothesized paths based on service role and outcome. For this purpose, we created two dummy variables (PCD1 and PCD2) based on the manipulation of target person ethnicity. Specifically, PCD1 has a value of 1 for the Caucasian target person and 0 for the other two, whereas PCD2 has a value of 1 for the South Asian target person and 0 for the other two. As a result, both these variables have a value of 0 for the Chinese target person, the target person with lowest PCD for all the participants, making it easy to interpret our results.

\section{Model 1 - Service Role as Moderator}

To test the moderating role of service role, we divided our sample into customer and employee groups and constrained each of the four links in our structural model one by one to be 
equal across the two groups. We then compared the fit indices for each of these constrained models with the unconstrained model to compare the strength of the path coefficients across the two groups. As shown in Table 5, the path coefficients for both PCD1 and PCD2 are negative for IC and SAT, which shows that the value of IC and SAT are lower for the Caucasian and South Asian target persons than those for the Chinese target person. Moreover, these path coefficients are significantly lower for employees compared to customers. In contrast, the positive path coefficients for IC on SQ and SQ on SAT are significantly higher for customers compared to the employees. Hence, the negative effects of PCD on IC (H3a) and SAT (H3d), and positive effects of IC on SQ (H3b) and SQ on SAT (H3c), are stronger for customers compared to employees.

$<$ Insert Tables 5 about here $>$

\section{Model 2 - Service Outcome as Moderator}

To test the moderating role of service outcome, we divided our sample into success and failure groups and followed the same procedure as above. As shown in Table 6, the negative path coefficients for PCD1 and PCD2 on both IC and SAT are significantly lower for service failure compared to success, whereas the positive path coefficients for IC on SQ and SQ on SAT are significantly higher for failure compared to success. Hence, the negative effects of PCD on IC (H6a) and SAT (H6d), and positive effects of IC on SQ (H6b) and SQ on SAT (H6c) are stronger for service failure compared to success, as shown in Table 6.

$$
<\text { Insert Tables } 6 \text { about here }>
$$

To conclude, we found support for all our hypotheses using an experimental methodology to manipulate PCD, service role and outcome. In the next section, we discuss all our findings along with their conceptual contribution and managerial implications. 


\section{DISCUSSION AND CONTRIBUTION}

In this paper, we extend the growing research on intercultural service encounters with a modified conceptual framework incorporating direct effects of perceived cultural distance on interaction comfort and satisfaction, as well as the influence of interaction comfort on perceived service quality and service quality on satisfaction, for both customers and employees. We also hypothesize that there is a moderating influence of service role (customer vs. employee) and service outcome (success vs. failure) on the above relationships. Finally, we hypothesize that there is an interaction between these two moderators (service role and service outcome) as well.

We used an experimental approach to test all our hypotheses, for greater control on the possible confounding influence of various external factors that plague other research methods such as critical incidence technique and survey. Using a between-subjects design with a sample of undergraduate business students, we manipulated service role, outcome and perceived cultural distance, using twelve versions of a basic scenario based on an intercultural service encounter in a restaurant setting, similar to Sharma et al. (2012). We found support for all our hypotheses.

We first tested the four main effects, namely the negative impact of PCD on IC and SAT, and the positive impact of IC on SQ, and SQ on SAT, to replicate and validate the findings reported in prior research. Specifically, using an experimental design and random assignment of the participants to the various conditions, allows us to tease out the impact of PCD without being confounded by any external factors. Hence, we found strong evidence for the negative influence of PCD on IC and SAT, unlike the mixed findings reported in prior research. This is an important finding as it shows that PCD does have an adverse impact on IC, SQ and SAT if we control for the effect of all other possible confounding factors, such as those reported in prior research (e.g., Sharma et al., 2012, Stauss and Mang, 1999). 
Next, we show that customers experience greater PCD and lower IC, SQ and SAT compared to employees. Similarly, the negative effects of PCD on IC and SAT, as well as the positive effects of IC on SQ and SQ on SAT are also stronger for customers compared to employees. All these findings confirm our basic contention that customers and employees have significantly different motivations, expectations and perceptions in intercultural service encounters, which affects their attitudes and behavior towards each other. These findings add to the current literature by including service role as moderator and exploring the direct impact of PCD on SAT as well as its indirect impact on SQ to provide deeper insights about the differences between customers and employees reported in prior research (e.g., Sharma et al., 2012).

We also show significant differences in IC, SQ and SAT between service success and failure. Prior research on intercultural service encounters mostly focused on service failures (e.g., Hopkins et al., 2005, Sharma et al., 2012, Stauss and Mang, 1999), hence by comparing our results across both success and failure in the same setting, we address the lack of empirical research on 'successful' intercultural encounters, a long standing research gap in this area. Moreover, we extend prior research by offering a comprehensive framework incorporating both service failure and success as possible outcomes in intercultural service encounters.

Finally, we also show significantly greater differences in the scores for IC, SQ and SAT between service success and failure, for customers compared to employees. To the best of our knowledge, this is the first evidence of an interaction between service role and outcome in the context of intercultural service encounters. By showing this interaction we make an important theoretical contribution to research in this research area of growing importance and relevance. Moreover, our comprehensive framework incorporates both service role and outcome as 
important moderators and thus provides a more complete picture of what happens in an intercultural service encounter involving customers and employees from different cultures.

\section{MANAGERIAL IMPLICATIONS}

Besides the above conceptual contributions, our research also offers many useful managerial insights. First, it shows that just like service customers, service employees may also experience the negative effect of PCD on their interaction comfort, perceived service quality and satisfaction. However, by showing that these effects are much stronger for the customers, we highlight the need to understand the customers' perspective in the intercultural service encounter, while paying attention to the views of the service employees as well. In other words, managers in service firms dealing with intercultural service encounters would find it useful to track not only their employees' attitudes and behaviors towards customers with different cultural backgrounds but also to monitor similar differences in the expectations and perceptions among customers.

Our findings also show that adopting a service employee's role may make people somewhat more tolerant towards culturally distant customers, possibly due to the nature of their jobs, role expectations and job requirements. Clearly, there is a need for the services managers to continue to understand and improve the attitudes of their employees towards customers from distant cultures; however it may be even more important to educate their customers about the cultural diversity in their workforce and to communicate the advantages as well as challenges of a diverse workforce to their customers and other stakeholders.

We also found that service failure causes greater influence of PCD on IC and SAT, as well as IC on SQ and SQ on SAT, compared to successful intercultural service encounters. In addition, customers experience greater differences in IC, SQ and SAT between service success and failure scenarios, compared to employees. Based on these findings, service managers may 
focus on service design and employee training geared towards preventing service failure rather than trying to improve the service quality and satisfaction beyond the customers' expectations. Moreover, they need to pay attention to the impact of PCD and IC on SQ and SAT for employees as well, even if these effects are weaker than those for the customers. Finally, they could use intercultural education and training to improve the knowledge, attitudes and behaviors towards each other for their culturally diverse customers and employees.

\section{LIMITATIONS AND FUTURE RESEARCH}

Despite making several important contributions, our research also has some limitations. First, we used the adapted versions of well-established scales with a small number of items for each scale to minimize participant fatigue and ensure their high involvement. For example, we used a three-item scale to measure perceived service quality, but some may argue that it could be measured as the gap between customer expectations and their perceptions of the quality of service received by them. However, prior research using both expectation-based and perceptionbased scales for service quality shows their scores to be highly correlated (e.g., Zeithaml et al., 1996), hence it seems more parsimonious to use shortened scales in research such as ours.

Second, we tried to minimize the possibility of any confounding effects of external variables such as customer knowledge, past experience and personal biases, by using an experimental design with imaginary service scenario and undergraduate students. However, this may restrict the generalizability of our findings and hence, future research may try to replicate our findings using other methodologies (e.g., critical incidence technique) with customers from diverse cultural, demographic and socio-economic backgrounds. Future research may also use scenarios with regular/loyal and first-time customers in diverse service settings besides 
restaurants such as airline travel, hotel stay, and holiday trip etc. to further test the generalizability of our findings.

Third, we controlled for gender effects in this study by using photos of only males as target persons (customer or employee); however, future research may find it useful to examine the role of gender differences in intercultural service encounters more systematically by manipulating it along with other variables (e.g., male customer vs. female employee etc.). Finally, we based our predictions about the moderating effects of service role and outcome using well-established theories about judgment biases (e.g., correspondence bias, self-serving attribution bias); however, we did not directly measure these biases. Future research could use approaches such as thought-listing or measure these biases directly, in order to test their role in the mechanism underlying the moderating effects hypothesized by us.

\section{REFERENCES}

Ali-Sulaiti, K.I. and Baker, M.J. (1998), "Country of origin effects: a literature review", Marketing Intelligence \& Planning, Vol. 16, No. 3, pp. 150-199.

Anderson, J.C. and Gerbing, D.W. (1988), "Structural equation modeling in practice: A review and recommended two step approach", Psychological Bulletin, Vol. 103, No. May, pp. $411-423$.

Bagozzi, R.P. and Yi, Y. (1988), "On the evaluation of structural equation models", Journal of the Academy of Marketing Sciences, Vol. 16, No. 1, pp. 74- 84.

Barker, S. and Härtel, C.E.J. (2004), "Intercultural Service Encounters: An Exploratory Study of Customer Experiences", Cross Cultural Management, Vol. 11, No. 1, pp. 3-14.

Bitner, M.J. (1990), "Evaluating service encounters: the effects of physical surroundings and employee responses", Journal of Marketing, Vol. 52, No. April, pp. 69-82.

Bitner, M.J., Booms, B.H. and Mohr, L.A. (1994), "Critical Service Encounters: The Employee's Viewpoint", Journal of Marketing, Vol. 58, No. October, pp. 95-106.

Bitner, M.J., Faranda, W.T., Hubbert, A.R. and Zeithaml, V.A. (1997), "Customer contributions and roles in service delivery", International Journal of Service Industry Management, Vol. 8, No. 3, pp. 193-205. 
Bradley, G.W. (1978), "Self-serving biases in the attribution process: A reexamination of the fact or fiction question", Journal of Personality and Social Psychology, Vol. 36, No. 1, pp. $56-71$.

Brady, M.K., Knight, G.A., Cronin, J.J.J., Hult, G.T.M. and Keillor, B.D. (2005), "Removing the Contextual Lens: A Multinational, Multi-Setting Comparison of Service Evaluation Models", Journal of Retailing, Vol. 81, No. 3, pp. 215-230.

Brown, S.P. and Lam, S.K. (2008), "A Meta-Analysis of Relationships Linking Employee Satisfaction to Customer Responses", Journal of Retailing, Vol. 84, No. 3, pp. 243-255.

Byrne, D.E. (1997), "An Overview (and Underview) of Research and Theory within the Attraction Paradigm", Journal of Social and Personal Relationships, Vol. 14, No. 3, pp. 417-431.

Chi, C.G. and Gursoy, D. (2009), "Employee satisfaction, customer satisfaction, and financial performance: An empirical examination", International Journal of Hospitality Management, Vol. 28, No. 2, pp. 245-253.

Chung-Herrera, B.G., Goldschmidt, N. and Hoffman, K.D. (2004), "Customer and employee views of critical service incidents", Journal of Services Marketing, Vol. 18, No. 4, pp. 241-254.

Dabholkar, P.A., Shepherd, C.D. and Thorpe, D.I. (2000), "A Comprehensive Framework for Service Quality: An Investigation of Critical Conceptual and Measurement Issues through a Longitudinal Study", Journal of Retailing, Vol. 76, No. 2, pp. 139-173.

de Matos, C.A., Fernandes, D.V.d.H., Leis, R.P. and Trez, G. (2011), "A Cross-Cultural Investigation of Customer Reactions to Service Failure and Recovery", Journal of International Consumer Marketing, Vol. 23, No. 3-4, pp. 211-228.

Dolen, W.v., Ruyter, K.d. and Lemmink, J. (2004), "An empirical assessment of the influence of customer emotions and contact employee performance on encounter and relationship satisfaction", Journal of Business Research, Vol. 57, No. 4, pp. 437-444.

Etgar, M. and Fuchs, G. (2011), "Does Ethnic/Cultural Dissimilarity Affect Perceptions of Service Quality?", Services Marketing Quarterly, Vol. 32, No. 2, pp. 113-128.

Fornell, C. and Larcker, D.F. (1981), "Evaluating Structural Equation Models with Unobservable Variables and Measurement Error", Journal of Marketing Research, Vol. 18, No. Feb, pp. $39-50$.

Gilbert, D.T. and Malone, P.S. (1995), "The correspondence bias", Psychological Bulletin, Vol. 117, No. 1, pp. 21-38.

Gremler, D.D., Bitner, M.J. and Evans, K.R. (1994), "The Internal Service Encounter", International Journal of Service Industry Management, Vol. 5, No. 2, pp. 34-56. 
Gremler, D.D. and Gwinner, K.P. (2000), "Customer-Employee Rapport in Service Relationships", Journal of Service Research, Vol. 3, No. 1, pp. 82-104.

Harrison-Walker, L.J. (1995), "The relative effects of national stereotype and advertising information on the selection of a service provider", Journal of Services Marketing, Vol. 9, No. 1, pp. 47-59.

Hopkins, S.A., Hopkins, W.E. and Hoffman, K.D. (2005), "Domestic inter-cultural service encounters: an integrated model", Managing Service Quality, Vol. 15, No. 4, pp. 329343.

Javalgi, R.G. and Martin, C.L. (2007), "Internationalization of services: identifying the buildingblocks for future research", Journal of Services Marketing, Vol. 21, No. 6, pp. 391-397.

Kleinot, M.C. \& Rogers, R.W. (1982), "Identifying Effective Components of Alcohol Misuse Prevention Programs", Journal of Studies on Alcohol and Drugs, Vol. 43, No. 7, pp. 802811.

Kulik, C.T. and Holbrook, R.L.J. (2000), "Demographics in Service Encounters: Effects of Racial and Gender Congruence on Perceived Fairness", Social Justice Research, Vol. 13, No. 4, pp. 375-402.

Liu, B.S.-c., Furrer, O. and Sudharshan, D. (2001), "The Relationships between Culture and Behavioral Intentions toward Services", Journal Of Service Research, Vol. 4, No. 2, pp. 118-129.

Martin, C.L. and Adams, S. (1999), "Behavioral biases in the service encounter: empowerment by default?", Marketing Intelligence \& Planning, Vol. 17, No. 4, pp. 192-201.

Mattila, A.S. (1999a), "The Role of Culture and Purchase Motivation in Service Encounter Evaluation", Journal of Services Marketing, Vol. 13, No. 4/5, pp. 376-389.

Mattila, A.S. (1999b), "The Role of Culture in the Service Evaluation Process", Journal of Service Research, Vol. 1, No. 3, pp. 250-261.

McCormick, A.E. and Kinloch, G.C. (1986), "Interracial contact in the customer-clerk situation", The Journal of Social Psychology, Vol. 126, No. 4, pp. 551-553.

Mohr, L.A. and Bitner, M.J. (1995), "The Role of Employee Effort in Satisfaction with Service Transactions", Journal of Business Research, Vol. 32, No. pp. 239-252.

Mudie, P. (2003), "Internal customer: by design or by default", European Journal of Marketing, Vol. 37, No. 9, pp. 1261-1276.

Nagel, P. and Cilliers, W. (1990), "Customer Satisfaction: A Comprehensive Approach", International Journal of Physical Distribution and Logistics, Vol. 20, No. 6, pp. 2-46. 
Ng, S.I., Lee, J.A. and Soutar, G.N. (2007), "Tourists' intention to visit a country: The impact of cultural distance", Tourism Management, Vol. 28, No. 6, pp. 1497-1506.

Oliver, R.L. (1997), Satisfaction: A Behavioral Perspective on the Consumer, New York, NY, McGraw-Hill. pp.

Parasuraman, A., Zeithaml, V.A. and Berry, L.L. (1988), "SERVQUAL: A multiple-item scale for measuring consumer perceptions of service quality", Journal of Retailing, Vol. 64, No. 1, pp. 12-37.

Paswan, A.K. and Ganesh, G. (2005), "Cross-Cultural Interaction Comfort and Service Evaluation", Journal of International Consumer Marketing, Vol. 18, No. 1/2, pp. 93-115.

Schneider, B. and Bowen, D.E. (1985), "Employee and customer perceptions of service in banks: Replication and extension", Journal of Applied Psychology, Vol. 70, No. 3, pp. 423-433.

Seiders, K., Voss, G.B., Grewal, D. and Godfrey, A.L. (2005), "Do Satisfied Customers Buy More? Examining Moderating Influences in a Retailing Context", Journal of Marketing, Vol. 69, No. October, pp. 26-43.

Sharma, P. (2005), "Exploring the Role of Ethnocentrism in Inter-cultural Service Encounters: Towards a Comprehensive Conceptual Framework", International Conference on Global Business in Services. Bali, Indonesia. pp.

Sharma, P., Tam, J.L.M. and Kim, N. (2009), "Demystifying Intercultural Service Encounters: Toward a Comprehensive Conceptual Framework", Journal of Service Research, Vol. 12, No. 2, pp. 227-242.

Sharma, P., Tam, J.L.M. and Kim, N. (2012), "Intercultural Service Encounters (ICSE) Framework: Extension and Empirical Validation", Journal of Services Marketing, Vol. 26, No. 7, pp. 521-534.

Sizoo, S. (2006), "A Comparison of the Effect of Intercultural Sensitivity on Employee Performance in Cross-Cultural Service Encounters: London vs. Florida", Journal of Euromarketing, Vol. 15, No. 4, pp. 77-100.

Sizoo, S., Plank, R., Iskat, W. and Serrie, H. (2005), "The effect of intercultural sensitivity on employee performance in cross-cultural service encounters", The Journal of Services Marketing, Vol. 19, No. 4, pp. 245-255.

Solomon, M.R., Surprenant, C., Czepiel, J.A. and Gutman, E.G. (1985), "A Role Theory Perspective on Dyadic Interactions: The Service Encounter", Journal of Marketing, Vol. 49, No. 1, pp. 99-111.

Sousa, C.M.P. and Bradley, F. (2006), "Cultural Distance and Psychic Distance: Two Peas in a Pod?", Journal of International Marketing, Vol. 14, No. 1, pp. 49-70. 
Spake, D.F., Beatty, S.E., Brockman, B.K. and Crutchfield, T.N. (2003), "Consumer Comfort in Service Relationships: Measurement and Importance", Journal of Service Research, Vol. 5, No. 4, pp. 316-332.

Stauss, B. and Mang, P. (1999), "'Culture Shocks" in Inter-cultural Service Encounters?", Journal of Services Marketing, Vol. 13, No. 4/5, pp. 329-346.

Tajfel, H., Billig, M., Bundy, R.P. and Flament, C. (1971), "Social categorization and intergroup behaviour", European journal of social psychology, Vol. 2, No. pp. 149-178.

Teng, C.-C. (2011), "Commercial hospitality in restaurants and tourist accommodation: Perspectives from international consumer experience in Scotland", International Journal of Hospitality Management, Vol. 30, No. 4, pp. 866-874.

Triandis, H.C. (1994), Culture and Social Behavior, New York, NY, McGraw Hill. pp.

Ueltschy, L.C., Laroche, M., Eggert, A. and Bindl, U. (2007), "Service quality and satisfaction: an international comparison of professional services perceptions", Journal of Services Marketing, Vol. 21, No. 6, pp. 410-423.

UNDESA (2011), "Trends in International Migrant Stock: The 2010 Revision". New York, United Nations Department of Economic and Social Affairs, Population Division. pp.

UNWTO (2012), "Inbound Tourist Arrivals", World Tourism Barometer. World Tourism Organization. pp. 1-9.

Wang, C.-y. and Mattila, A.S. (2010), "A grounded theory model of service providers' stress, emotion, and coping during intercultural service encounters", Managing Service Quality, Vol. 20, No. 4, pp. 328-342.

Wang, C.-y. and Mattila, A.S. (2011), "A cross-cultural comparison of perceived informational fairness with service failure explanations", Journal of Services Marketing, Vol. 25, No. 6, pp. 429-439.

Warden, C.A., Liu, T.-C. and Huang, C.-T. (2003), "Service Failures Away from Home: Benefits in Intercultural Service Encounters", International Journal of Service Industry Management, Vol. 14, No. 4, pp. 436-457.

Weiermair, K. (2000), "Tourists' perceptions towards and satisfaction with service quality in the cross-cultural service encounter: implications for hospitality and tourism management", Managing Service Quality, Vol. 10, No. 6, pp. 397-409.

Zeithaml, V.A., Berry, L.L. and Parasuraman, A. (1996), "The behavioral consequences of service quality", Journal of Marketing, Vol. 60, No. 2, pp. 31-46.

Zhang, J., Beatty, S.E. and Walsh, G. (2008), "Review and future directions of cross-cultural consumer services research", Journal of Business Research, Vol. 61, No. 3, pp. 179-182. 